\title{
Use of Aeroponic Chambers and Grafting to Study Partial Resistance to Fusarium solani f. sp. glycines in Soybean
}

\author{
D. S. Mueller and S. Li, Department of Crop Sciences, University of Illinois; G. L. Hartman, United States De- \\ partment of Agriculture-Agricultural Research Service; and W. L. Pedersen, Department of Crop Sciences, Univer- \\ sity of Illinois, Urbana 61801
}

\begin{abstract}
Mueller, D. S., Li, S., Hartman, G. L., and Pedersen, W. L. 2002. Use of aeroponic chambers and grafting to study partial resistance to Fusarium solani f. sp. glycines in soybean. Plant Dis. 86:1223-1226.

Several plant introductions (PIs) and cultivars have been classified as partially resistant (PR) to sudden death syndrome. However, little is known about the nature of resistance to this disease. Seedlings of two PR PIs and two susceptible cultivars were inoculated with Fusarium solani f. sp. glycines in aeroponic chambers. Plants were inoculated by taping two sorghum seeds infested with $F$. solani f. sp. glycines to the main root. Foliar symptoms of the susceptible cultivars were higher than those on the PR PIs and were associated with lower root and plant dry weight. Root lesion lengths of the four soybean lines differed $(P<0.05)$, but did not correlate with foliar disease or any other variable. To better understand the resistance mechanism by distinguishing between root and plant resistance, three partially resistant PIs (PI 520.733, PI 567.374, and PI 567.650B) and one susceptible soybean cultivar (GL3302) were compared using different grafting combinations in aeroponic chambers. Results of sudden death syndrome evaluation indicated that resistance is conditioned by both the scion and the rootstock. All three PIs evaluated had resistance associated with the scion; resistance in PI 567.650B also was associated with the rootstock. Although the PR PIs used appear to have little or no root resistance, an aeroponic system and grafting may help identify new sources of resistance to $F$. solani f. sp. glycines with root- or whole-plant resistance.
\end{abstract}

Sudden death syndrome of soybean (Glycine max (L.) Merr.) is caused by the soilborne fungus Fusarium solani (Mart.) Sacc. f. sp. glycines (17). The fungus infects the soybean roots and causes root rot, crown rot, and vascular discoloration in stems. However, the most recognizable symptoms of sudden death syndrome are on the leaves. F. solani f. sp. glycines produces a toxin which appears to translocate to the upper leaves, causing characteristic foliar symptoms that begin as chlorotic mottling and proceed to interveinal chlorosis and necrosis, with eventual defoliation $(17,18)$.

One disease management option to reduce the severity of sudden death syn-

\section{Corresponding author: W. L. Pedersen}

E-mail: wpederse@uiuc.edu

This research would not have been possible without the financial support of the Illinois Soybean Operating Board.

Names are necessary to report factually on available data; however, the USDA neither guarantees nor warrants the standard of the product, and the use of the name by USDA implies no approval of the product to the exclusion of others that may also be suitable.

Accepted for publication 6 June 2002

Publication no. D-2002-0903-02R

(C) 2002 The American Phytopathological Society drome is to plant less susceptible cultivars. Differences in disease susceptibility among soybean cultivars and plant introductions (PIs) have been observed $(6,9,12,14,17)$. Sudden death syndrome foliar symptoms are relatively easy to identify; therefore, most efforts to evaluate sudden death syndrome resistance in soybean are based on foliar symptoms $(6,9,11,18)$. Less effort has been made to characterize root resistance to $F$. solani f. sp. glycines, although it has been reported $(12,14)$. One report based root resistance on the number of $F$. solani f. sp. glycines CFU obtained from root tissue and showed that resistant cultivars had significantly fewer CFU/g of root tissue (12). In another report, soybean lines that showed partial resistance based on foliar symptoms of seedlings did not exhibit any differences in root lesion length compared with susceptible cultivars (9). Although partially resistant soybean lines have been identified, either by foliar symptoms or CFU in roots, there is little information on the morphological location of the resistant response.

The use of aeroponic chambers may provide a method to evaluate soybean plants for root resistance to $F$. solani f. sp. glycines. The system is ideal for visually monitoring roots that have been inoculated without destroying plants. Sudden death syndrome has two distinct stages; therefore, the ability to evaluate plants simultaneously for both the root rot and the foliar symptoms may help identify more desirable sources of resistance, which may improve genetic resistance in modern cultivars. Wagner and Wilkinson (19) used an aeroponic system to enable nondestructive examination of disease development on soybean taproots inoculated with Phytophthora sojae. Aeroponic systems also have been used for evaluating root resistance on other crops, including maize (3), pea (16), and wheat (8).

Grafting combinations have been used to understand resistance mechanisms by locating the tissue or tissues responsible for resistance. Several studies have been conducted using grafted soybean plants to examine resistance to brown stem rot, caused by the fungus Phialophora gregata, which is another soilborne pathogen causing root and foliar symptoms $(1,10,15)$. Bachman and Nickell (1) reported that roots conditioned resistance to brown stem rot. Prior to Bachman and Nickell's report, results were not consistent because both aerial (10) and root (15) resistance was reported.

Although grafting and aeroponic chambers have been used to study other soybean diseases, neither of these has been used previously to study sudden death syndrome. The objectives of this study were to investigate resistance of soybean in an aeroponics system and to identify whether resistance was conditioned by the rootstock or scion using three partially resistant PIs in different grafting combinations.

\section{MATERIALS AND METHODS}

Aeroponic chambers study. Aeroponic chambers ( 80 by 60 by $60 \mathrm{~cm}$ ) were used to evaluate resistance in soybean to $F$. solani f. sp. glycines. Tops consisted of 1.5cm-thick Poly Hi Solidur plastic with 70 holes, $1 \mathrm{~cm}$ in diameter, drilled on $5-\mathrm{cm}$ centers. Bolts, $10 \mathrm{~cm}$ long and $0.7 \mathrm{~cm}$ in diameter, were installed along the top edges $5 \mathrm{~cm}$ apart. Rubber bands stretched across these bolts created a grid overlying the holes. The rubber bands served as support for the growing plants and were raised as needed. A controller (ChronTrol Corp., San Diego, CA) was set to mist the roots for $2 \mathrm{~s}$ every $7 \mathrm{~min}$ using greenhouse air supply pressurized $(552 \mathrm{kPa}) \quad 20$-liter stainless steel tanks (MIDCO, Rock Island, IL) filled with half-strength nutrient solution (7). An inline filter (AA122-PP Compact Liquid Strainer; Spraying Systems 
Co., Wheaton, IL) was added to keep the eight stainless steel atomizing nozzles (1/4 LNN; Spraying Systems Co.) in the chamber clean. Mean room temperature was $24^{\circ} \mathrm{C}$, with a range of 22 to $27^{\circ} \mathrm{C}$. The photosynthetically active radiation (PAR) was $434 \mu \mathrm{E} \mathrm{m}^{-2} \mathrm{~s}^{-1}$.

Two partially resistant PIs, PI 520.733 and PI 567.374, and two susceptible cultivars, Great Lakes 3302 (GL3302) and Spencer (9), were evaluated. Soybean seed were grown in sand until the VC growth stage (4), then placed into the aeroponic chambers (6 days after planting). Seedlings were shaded the first day to reduce stress from the transfer. The following day, sorghum seed either infested or not infested with $F$. solani f. sp. glycines were taped directly to the primary taproot for inoculated and noninoculated plants, respectively. Inoculum was prepared by soaking $200 \mathrm{~cm}^{3}$ of sorghum grain in distilled water in a 1-liter Erlenmeyer flask overnight (13). Excess water was drained and the grain autoclaved for $60 \mathrm{~min}$ at $121^{\circ} \mathrm{C}$ on consecutive days and allowed to cool. After cooling, 10 plugs, $6 \mathrm{~mm}$ in diameter, containing mycelia of $F$. solani f. sp. glycines isolate Mont-1 (P. Stevens, Illinois; 5) on water agar were added to the flask. The flask was shaken daily and incubated at $24^{\circ} \mathrm{C}$ under continuous fluorescent light $\left(60 \mu \mathrm{E} \mathrm{m}^{-2} \mathrm{~s}^{-1}\right)$. After 10 days of growth, inoculum was stored at $4^{\circ} \mathrm{C}$. When inoculating plants, Scotch tape (3M Co., St. Paul, MN) was used to attach two infested sorghum seeds in direct contact with the primary root, approximately where the highest secondary root emerged. The same technique was used to attach noninfested

Table 1. Mean foliar severity ratings and lesion lengths on soybean roots of two partially resistant plant introductions (PIs) and two susceptible soybean cultivars after inoculating roots with Fusarium solani f. sp. glycines in aeroponic chambers ${ }^{\mathrm{a}}$

\begin{tabular}{lcc}
\hline Soybean line $^{\mathbf{b}}$ & $\begin{array}{c}\text { Foliar } \\
\text { rating (\%) }^{\mathbf{c}}\end{array}$ & $\begin{array}{c}\text { Lesion } \\
\text { length (mm) }\end{array}$ \\
\hline GL3302 (S) & 75 & 34 \\
Spencer (S) & 58 & 37 \\
PI 520.733 (PR) & 14 & 40 \\
PI 567.374 (PR) & 28 & 28 \\
LSD $_{(0.05)}$ & 14 & 7 \\
\hline
\end{tabular}

a Values are means of eight replications, with each replication having between three and four seedlings per soybean line.

${ }^{\mathrm{b}} \mathrm{S}=$ susceptible and $\mathrm{PR}=$ partially resistant to $F$. solani $\mathrm{f}$. sp. glycines. LSD = least significant difference.

${ }^{c}$ Disease ratings were based on a 1-to-9 scale, where $1=$ no symptoms; 2 to $4=$ light symptom development ( 1 to 5,5 to 10 , and 10 to $20 \%$ foliage affected); 5 and $6=$ moderate symptom development (20 to 35 and 35 to $50 \%$ foliage affected); 7 and $8=$ heavy symptom development (50 to 65 and 65 to $80 \%$ foliage affected); and $9=$ severe symptom development (81 to $100 \%$ foliage affected). Data were converted to midpoint values (2) based on range within each severity rating scale. seed to the primary root of the noninoculated plants. Each aeroponic chamber was split, each half treated as a replication. One replication consisted of two treatments (inoculated and noninoculated) and seven plants of each line, four inoculated and three noninoculated. The noninoculated and inoculated soybean lines were randomly placed within each of the four replications. At 18 days after placing the soybean seedlings in the aeroponic chambers, data were recorded on root dry weight and lesion length; and on plant dry weight and foliar symptoms. The percentage of reduction from the noninoculated control was calculated for root and plant dry weight by using [1 - (inoculated/mean noninoculated) $\times 100$. Foliar ratings were based on a 1 to 9 rating scale, where $1=$ no symptoms; 2 to $4=$ light symptom development ( 1 to 5,5 to 10 , and 10 to $20 \%$ foliage affected); 5 and $6=$ moderate symptom development (20 to 35 and 35 to $50 \%$ foliage affected); 7 and $8=$ heavy symptom development (50 to 65 and 65 to $80 \%$ foliage affected); and $9=$ severe symptom development (81 to $100 \%$ foliage affected) (13). The experiment was completed twice.

Grafting study. Aeroponic chambers were similar to the previously described chambers with a few exceptions. The chambers were 60 by 60 by $60 \mathrm{~cm}$ and had 64 holes. Soybean seedlings were grafted using rootstocks and scions of partially resistant PIs (PI 520.733, PI 567.374, and PI 567.650B) and one susceptible cultivar (GL3302). The different grafting combinations were (i) rootstock and scion from the same soybean line (PI 520.733 self-grafted, PI 567.374 self-grafted, PI 567.650B selfgrafted, and GL3302 self-grafted); and (ii) rootstock and scion from different soybean lines (PI 520.733 root and GL3302 scion, PI 567.374 root and GL3302 scion, PI 567.650B root and GL3302 scion, GL3302 root and PI 520.733 scion, GL3302 root and PI 567.374 scion, and GL3302 root and PI 567.650B scion). The soybean grafting technique published by Bachman and Nickell (1) was used. Soybean seed were planted in flats ( 45 by 35 by $10 \mathrm{~cm}$ ) filled with sand. At the VE growth stage (6 days after planting) (4), grafts were made by transversely severing the hypocotyl approximately $2 \mathrm{~cm}$ below the cotyledons with a razor. The lower portion remained in the sand and became the rootstock and the upper portion became the scion. A vertical incision, $1.0 \mathrm{~cm}$ deep, was made with a razor into the top of the rootstock. A 1.5to $2.5-\mathrm{cm}$ section of a drinking straw (3 $\mathrm{mm}$ in diameter) was slit lengthwise with a razor, slipped over the rootstock, and allowed to fall to the base. The scion was cut into a V-shaped-wedge, which was inserted into the rootstock incision. The graft was secured by lifting the straw into place. Both the grafted and nongrafted seedlings were placed in a plastic chamber on a greenhouse bench containing a humidifier and humidistat (Herrmidifier Co. Inc., Lancaster, PA). The seedlings were kept at $100 \%$ humidity for 3 days. On the fourth day, the humidistat was lowered to $90 \%$ relative humidity, and the plastic sheet was lifted slightly on the fifth day, further lowering the humidity. On the sixth day, the plastic sheet was removed and the humidifier turned off. Seven days after grafting (13 days after planting), the seedlings were removed from the sand and placed in aeroponic chambers, shaded for 1 day, then inoculated with $F$. solani f. sp. glycines (14 days after planting). Inoculum preparation and inoculation technique was done as described in the previous study.

Three plants of each grafted combination, plus two to three nongrafted seedlings of each soybean line, were randomly placed into three aeroponic chambers, each representing a replication. The grafted and nongrafted combinations were arranged in a randomized complete block design. Ratings were taken 30 days after planting using the previously mentioned 1-to-9 scale. Disease severity ratings were converted to percent midpoint values (2). The experiment was completed twice.

Data analysis. For the aeroponic chamber study, means from each replication were analyzed by analysis of variance (ANOVA) using replications and trials as random effects and treatments and soybean line as fixed effects. Means of the inoculated and noninoculated plants were compared by single degree of freedom contrasts, while means of the soybean lines were compared by Fisher's protected least significant difference (LSD) at $P<0.05$. A Pearson's correlation coefficient was calculated among foliar symptoms, root lesion length, root dry weight, and plant dry weight using the SAS Pearson correlation procedure (PROC CORR). For the grafting study, the means for the three plants in each replication were analyzed using a two-way ANOVA, in which the main effects of rootstock and scion were tested (SAS Institute, Cary, NC). Nongrafted controls were not included in the analysis.

\section{RESULTS}

Aeroponic chambers study. Data from the repeated experiments were combined because there was not a significant trialsoybean line interaction and the error variances were homogeneous. GL3302 and Spencer had higher foliar disease severity ratings than PI 520.733 and PI 567.374 (Table 1). Differences were found in root lesion length because PI 567.374 had shorter lesion lengths $(P<0.05)$ when inoculated compared with Spencer and PI 520.733. All four soybean lines had significant root and plant dry weight reductions after inoculation with $F$. solani $\mathrm{f}$. sp. glycines compared with the noninoculated plants. Root weight reduction ranged from 25 to $68 \%$ and plant weight reduction ranged from 36 to $59 \%$ (Table 2). Foliar 
symptoms were negatively correlated with root and plant weight but not correlated with root lesion length. Lesion length was not correlated with root and plant weight (Table 3).

Grafting study. Using trial $x$ root $\times$ scion as the error term, trial $(P=0.28, P=$ $0.34)$, trial $\times \operatorname{root}(P=0.29, P=0.62)$, and the trial $\times$ scion $(P=0.08, P=0.67)$ were found to be not significant for foliar ratings and root lesion length, respectively. Therefore, data from the two trials were combined. Nongrafted plants were not included in the two-way ANOVA. The means for the nongrafted GL3302 was $77 \%$ foliar symptoms, which was higher than PI 520.733 (15\%), PI 567.374 (17\%), and PI $567.650 \mathrm{~B}(24 \%)$. The nongrafted means were similar to the self-grafted plants, indicating that grafting did not affect disease development. From the two-way ANOVA, both root $(P=0.0237)$ and scion $(P<0.0001)$ had a significant effect on foliar symptoms; however, the root-scion interaction was not significant $(P=$ 0.1311). Plants with PI 567.650B rootstock (27\%) had significantly lower foliar symptoms than plants with GL3302 (38\%) and PI $520.733(40 \%)$ rootstock. Plants with GL3302 scion $(51 \%)$ had significantly more foliar symptoms than plants with scions from the PIs (20 to $28 \%$; Table 4 ). There were differences in the nongrafted check for root lesion length (PI 520.733 had the longest lesion length and PI 567.374 had the shortest lesion length); however, there were no differences for the grafted plants (Table 4).

\section{DISCUSSION}

For both the aeroponic study and the grafting study, the aeroponic chambers provided a unique, yet favorable environment for soybean plants to grow. Infection by secondary inoculum was not observed and may have been prevented by not recirculating the spent nutrient solution. In the aeroponics study, roots of noninoculated plants appeared healthy and grew robustly in the same aeroponic chambers as inoculated plants. Using the aeroponic system to study sudden death syndrome provides easily assessable disease data on roots and the foliage. Similar to previous studies, the aeroponic system was used to enable nondestructive examination of disease development on different crops $(3,8,16)$, including soybean (19). In the aeroponic chambers, the roots that have been inoculated could be visually monitored without destroying plants. The taproot inoculation technique was rapid with minimal damage to the roots.

For this study, foliar symptoms for the four soybean lines were comparable to foliar symptoms of the same soybean lines grown in Cone-Tainers (9). The foliar reaction of these four soybean lines to $F$. solani f. sp. glycines already was known $(6,9)$. Although it has not been published, both of the partially resistant (PR) PIs have shown high levels of resistance, and Spencer and GL3302 have been very susceptible in the field. Root lesion lengths and root dry weight reductions for these lines differed from previous studies. Huang and Hartman (9) reported lesion lengths of 33 to $39 \mathrm{~mm}$ and root dry weight losses ranging from 59 to $74 \%$ with no statistical differences. The lesion lengths in the aeroponic chambers ranged from 28 to $40 \mathrm{~mm}$ and significant differences were found. Additionally, there was a distinct split between the PR and the susceptible soybean lines in root dry weight loss, with the PR soybean lines having significantly less root dry weight loss. Root dry weight may be more accurate in the aeroponic chambers compared

Table 4. Sudden death syndrome foliar ratings and root lesion lengths from different grafting combinations between three partially resistant plant introductions (PIs) and one susceptible cultivar inoculated with $F$. solani f. sp. glycines ${ }^{\mathrm{a}}$

\begin{tabular}{lcccccc}
\hline & & \multicolumn{2}{c}{ Foliar rating (\%) } & & \multicolumn{2}{c}{ Lesion length $(\mathbf{m m})$} \\
\cline { 6 - 7 } Soybean line & No. observations & Root $^{\mathbf{b}}$ & Scion $^{\mathbf{c}}$ & & Root $^{\mathbf{b}}$ & Scion $^{\mathbf{c}}$ \\
\hline GL3302 & 24 & 38 & 51 & & 34 & 34 \\
PI 520.733 & 12 & 40 & 20 & & 39 & 37 \\
PI 567.374 & 12 & 31 & 22 & & 31 & 32 \\
PI 567.650B & 12 & 27 & 28 & & 35 & 34 \\
LSD $_{(0.05)}{ }^{\mathbf{d}}$ & $\cdots$ & 9 & 9 & & n.s. & n.s. \\
\hline
\end{tabular}

${ }^{\text {a }}$ Disease ratings were based on a 1-to-9 scale, where $1=$ no symptoms; 2 to $4=$ light symptom development ( 1 to 5,5 to 10 , and 10 to $20 \%$ foliage affected); 5 and $6=$ moderate symptom development (20 to 35 and 35 to $50 \%$ foliage affected); 7 and $8=$ heavy symptom development (50 to 65 and 65 to $80 \%$ foliage affected); and $9=$ severe symptom development ( 81 to $100 \%$ foliage affected). Data were converted to midpoint values (2) based on range within each severity rating scale; n.s. = not significant.

${ }^{b}$ Data calculated from all grafting combinations that included the rootstock of respective soybean line.

${ }^{c}$ Data calculated from all grafting combinations that included the scion of respective soybean line.

${ }^{\mathrm{d}}$ LSD $=$ least significant difference.

Table 2. Mean root and plant dry weight of two partially resistant plant introductions (PIs) and two susceptible soybean cultivars after inoculating roots with Fusarium solani f. sp. glycines in aeroponic chambers ${ }^{\mathrm{a}}$

\begin{tabular}{|c|c|c|c|c|c|c|}
\hline \multirow[b]{2}{*}{ Soybean line $^{b}$} & \multicolumn{3}{|c|}{ Root dry weight (g) } & \multicolumn{3}{|c|}{ Plant dry weight (g) } \\
\hline & Inoculated & Noninoculated & Percent reduction $^{c}$ & Inoculated & Noninoculated & Percent reduction \\
\hline GL3302 (S) & $0.19^{\mathrm{d}}$ & 0.37 & 50 & $0.21^{\mathrm{d}}$ & 0.46 & 54 \\
\hline Spencer (S) & $0.12^{\mathrm{d}}$ & 0.37 & 68 & $0.24^{\mathrm{d}}$ & 0.58 & 59 \\
\hline PI 520.733 (PR) & $0.30^{\mathrm{d}}$ & 0.44 & 32 & $0.57^{\mathrm{d}}$ & 0.89 & 36 \\
\hline PI 567.374 (PR) & $0.18^{\mathrm{d}}$ & 0.24 & 25 & $0.22^{\mathrm{d}}$ & 0.36 & 39 \\
\hline $\operatorname{LSD}_{(0.05)}$ & 0.03 & 0.07 & 11 & 0.05 & 0.14 & 11 \\
\hline
\end{tabular}

${ }^{a}$ Values are means of eight replications, with each replication having between three and four seedlings per soybean line.

${ }^{\mathrm{b}} \mathrm{S}=$ susceptible and $\mathrm{PR}=$ partially resistant to $F$. solani $\mathrm{f}$. sp. glycines. $\mathrm{LSD}=$ least significant difference.

${ }^{c}$ Percent reduction from noninoculated root length and root dry weight was calculated by $[1-$ (inoculated/mean noninoculated) $] \times 100$

${ }^{\mathrm{d}}$ Inoculated and noninoculated significantly different at $P<0.05$.

Table 3. Pearson's correlations coefficients of values for foliar ratings, lesion length, root length and weight, and shoot height and weight for soybean plants inoculated with Fusarium solani f. sp. glycines in aeroponic chambers ${ }^{\mathrm{a}}$

\begin{tabular}{|c|c|c|c|c|c|}
\hline Values $^{\mathrm{b}}$ & Lesion length (mm) & Root dry weight (g) & Root dry weight $(\%)^{\mathrm{c}}$ & Shoot dry weight (g) & Shoot dry weight $(\%)^{\mathrm{c}}$ \\
\hline Foliar ratings (\%) & -0.05 (n.s.) & $-0.37(0.02)$ & $-0.49(0.002)$ & $-0.64(0.001)$ & $-0.55(0.001)$ \\
\hline Lesion length (mm) & $\ldots$ & -0.19 (n.s.) & 0.03 (n.s.) & 0.10 (n.s.) & -0.20 (n.s.) \\
\hline
\end{tabular}

${ }^{\mathrm{a}}$ Values in parentheses are probabilities; n.s. = not significant.

${ }^{\mathrm{b}}$ Disease ratings were based on a 1-to-9 scale, then converted to midpoint values (2) based on range within each severity rating scale.

${ }^{c}$ Percent reduction from noninoculated root length, root dry weight, shoot height, and shoot dry weight was calculated by [1 - (inoculated/mean noninoculated) $] \times 100$. 
with other field and greenhouse evaluation techniques because roots are not lost when sampling and root growth is not restricted.

Using these soybean lines within the aeroponic system, foliar symptoms were associated with a reduction in root and plant weight, whereas root lesion length was not correlated with foliar disease or root and plant weight.

As can be seen by the discrepancy in foliar symptom evaluations compared with root evaluations, there is neither a quick nor easy way to evaluate roots when there are many soybean entries. Using the aeroponics system may be the solution to this problem. There are a couple of advantages in identifying root resistance. First, if high levels of root resistance were available, it may make resistance to the foliar symptoms unnecessary. If a plant's roots never become infected with $F$. solani f. sp. glycines, there would not be toxin production and the subsequent foliar symptoms later in the season. A second advantage would be to reduce plant stress and yield loss associated with the root rot phase of sudden death syndrome.

Grafting was used to locate the tissue or tissues responsible for resistance. In this study, resistance was associated with both the scion and the rootstock. Although all three PIs had resistance associated with the scion, PI 567.650B also had low levels of resistance located in the root. However, root lesion lengths of PI 567.650B were not lower than the other soybean lines. We have defined the root resistance in PI $567.650 \mathrm{~B}$ as a reduction in foliar symptoms with the addition of a "resistant" root. This is not comparable to root resistance as defined by Njiti et al., using CFU as the resistance parameter (14).

Unlike the root-limited resistance in soybean plants for brown stem rot resistance (1), resistance to sudden death syn- drome mostly is limited to the scion or aerial part of the plant. It appears that the current evaluations $(6,13)$ used to identify new sources of resistance are selecting for resistance conditioned by the aerial part of the plant. Although implementing sources of resistance like PI 520.733 and PI 567.374 into breeding programs may improve resistance to $F$. solani $\mathrm{f}$. sp. glycines in the foliar symptom stage, using sources with high levels of root resistance or whole-plant resistance may improve both resistance to the root rot and the foliar symptom stages. Evaluating more soybean lines with aeroponic chambers and grafting may help identify lines with root- or whole-plant resistance.

\section{ACKNOWLEDGMENTS}

We thank K. Ames, C. Bradley, S. Casteel, C. Dotterer, M. Gardner, C. Kleinschmidt, C. Leman, J. Mueller, R. Warsaw, and C. Weeks for their assistance in grafting and maintenance of the aeroponic chambers; and M. Bachman for his initial ideas and teaching the grafting techniques.

\section{LITERATURE CITED}

1. Bachman, M. S., and Nickell, C. D. 1999. Use of reciprocal grafting to study brown stem rot resistance in soybean. Phytopathology 89:59-63.

2. Campbell, C. L., and Madden, L. V. 1990. Introduction to Plant Epidemiology. John Wiley \& Sons, New York.

3. du Toit, L. J., Kirby, H. W., and Pedersen, W. L. 1997. Evaluation of an aeroponic system to screen maize genotypes for resistance to Fusarium graminearum seedling blight. Plant Dis. 81:175-179.

4. Fehr, W. R., Caviness, C. E., Burmood, D. T., and Pennington, J. S. 1971. Stage of development descriptions for soybeans, Glycine $\max ($ L.) Merrill. Crop Sci. 11:929-931.

5. Gray, L. E., and Achenbach, L. A. 1996. Severity of foliar symptoms and root and crown rot of soybean inoculated with various isolates and inoculum rates of Fusarium solani. Plant Dis. 80:1197-1199.

6. Hartman, G. L., Huang, Y. H., Nelson, R. L., and Noel, G. R. 1997. Germplasm evaluation of Glycine max for resistance to Fusarium solani, the causal organism of sudden death syndrome. Plant Dis. 81:515-518.

7. Hoagland, D. R., and Arnon, D. I. 1950. The water culture method for growing plants without soil. Calif. Agric. Exp. Stn. Circ. 347.

8. Hoffman, T. K., and Kolb, F. L. 1997. Effects of barley yellow dwarf virus on root and shoot growth of winter wheat seedlings grown in aeroponic culture. Plant Dis. 81:497-500.

9. Huang, Y. H., and Hartman, G. L. 1998. Reaction of selected soybean genotypes to isolates of Fusarium solani f. sp. glycines and their culture filtrates. Plant Dis. 82:999-1002.

10. Kunkel, J. F., and Dunleavy, J. M. 1965 Brown stem rot development in soybeans. (Abstr.) Phytopathology 55:1065.

11. Li, S., Hartman, G. L., and Widholm, J. M. 1999. Viability staining of soybean suspension-cultured cells and a seedling stem cutting assay to evaluate phytotoxicity of Fusarium solani f. sp. glycines culture filtrates. Plant Cell Rep. 18:375-380.

12. Luo, Y., Myers, O., Lightfoot, D. A., and Schmidt, M. E. 1999. Root colonization of soybean cultivars in the field by Fusarium solani f. sp. glycines. Plant Dis. 83:1155-1159.

13. Mueller, D. S., Hartman, G. L., Nelson, R. L., and Pedersen, W. L. Evaluation of Glycine max germ plasm for resistance to Fusarium solani f. sp. glycines. Plant Dis. 86:741-746.

14. Njiti, V. N., Suttner, R. J., Gray, L. E., Gibson, P. T., and Lightfoot, D. A. 1997. Ratereducing resistance to Fusarium solani f. sp. phaseoli underlies field resistance to soybean sudden death syndrome. Crop Sci. 37:132138.

15. Phillips, D. V. 1971. Influence of air temperature on brown stem rot of soybean. Phytopahtology 61:1205-1208.

16. Rao, A., Gritton, E. T., Grau, C. R., and Peterson, L. A. 1995. Aeroponics chambers for evaluating resistance to Aphanomyces root rot of peas (Pisum sativum). Plant Dis. 79:128-132.

17. Roy, K. W., Rupe, J. C., Hershman, D. E., and Abney, T. S. 1997. Sudden death syndrome of soybean. Plant Dis. 81:1100-1111.

18. Rupe, J. C. 1989. Frequency and pathogenicity of Fusarium solani recovered from soybeans with sudden death syndrome. Plant Dis. 73:581-584.

19. Wagner, R. E., and Wilkinson, H. T. 1992. An aeroponics system for investigating disease development on soybean taproots infected with Phytophthora sojae. Plant Dis. 76:610-614. 